\title{
History, Agency, and the Power of Music
}

The music system that came to represent modern Iran's authentic and historic Persian culture originated from a set of musical customs distinct from the twelvemaqam system. It ultimately became a method of music-making organized around the notion of a distinct music tradition for the nation of Iran, and with this changing view of music's meaning came new options for its organization and execution. In its earliest documented form, the initial seven dastgahs' poetic-procedural approach to musical performance related to broad transregional trends in contexts that appear to be nonliterate. Such was the historical reality of West and Central Asia beyond the contexts relating directly to dynastic rule, the contexts that controlled the erudite written word and the twelve-maqam system.

Modern Iran's active intervention with the particular music tradition of Mirza 'Abdullah and Hossein Qoli would ultimately change the seven dastgah of the Qajar courts into the radif-dastgah tradition of the Iranian nation. Yet the modern creation of the nation and the ongoing construction and reconstruction of its identity did not provide one answer for how music could best demonstrate Iran's Persian identity and history. There would ultimately be more than one way to perform music in the radif-dastgah tradition, depending on which aspect of its Iranian-ness was emphasized: the idiosyncratic Persian musical material of the radif, systematic modality in imitation of what had existed in the twelve-maqam system, or the poetry of Iran's medieval golden age. The delineation of these three distinct elements in the twentieth century changed the music's structural definition, while also providing flexibility in its modern interpretation. This flexibility allowed musicians to vary the music's conception and performance practice, even as different variations could reflect different ideas about the correct expression of 
Iranian culture. Their decisions about how to perform and teach the tradition were artistic and subject to individual artists' concepts of indigenous musical expression. Yet they were also fundamentally political decisions, with moral implications for the nation as a whole.

In this sense, the radif-dastgah tradition did not simply appear suddenly as a contrived phenomenon of the modern era. Modernity did not entail complete amnesia about indigenous musical praxis; rather, it required a particular reexamination of indigenous culture on specifically modern terms, and this reexamination began in the dynastic courts, which had recently been affected by significant localized political instability shortly before modernity's global structures came to be dominant political realities of the region. This contingent situation opened up the Qajar court to new possibilities for musical entertainment, both indigenous and European. Qajar entertainment ultimately provided a cultural basis for music's interpretation and reinterpretation within the modern framework of Iranian nationhood, and the seven dastgah held a special place in this renegotiation of culture. The Iranian nation's need for its own unique musical heritage of ancient import placed much emphasis on music's indigenous idiosyncrasy, yet developing narratives about the nation's history and culture would raise questions about how to resolve this idiosyncrasy with the twelve-maqam system, as this older concept of music came to define Iran's musical past.

Ultimately there would never be one agreed-upon way to approach the radifdastgah tradition to properly balance the need for cultural idiosyncrasy with historical consistency within Iranian identity. At the turn of the twenty-first century, musicians were still finding new ways of analyzing and approaching the radif-dastgah tradition that reframed the question of melodic procedures versus systematic modality in different ways. ${ }^{1}$ While in Iran in 2003 , I studied the seven dastgah with a musician whom my Iranian musicologist colleagues consistently described as a "radif player": a musician who strictly maintained the gusheh of the seven dastgah as a set canon that must be taught and executed with little room for embellishment or alteration. This practice was perfectly normal in Tehran while I was there, but was also criticized by Iranian musicologists and musicians alike. Certainly the earliest practice never intended for a strict memorization of the melodies as a repertoire overall, distinct from poetry and the dastgah performance context. Yet the radif is now a central codified repertoire that actively demonstrates the existence of Iranian identity and history. Playing it as a set musical whole is a way for musicians to perform Iranian identity in the twenty-first century. From this perspective, radif-playing is no less culturally legitimate than any other approach to performing in the radif-dastgah tradition.

Since the Islamic Revolution in 1979, musicians of the radif-dastgah tradition like the tar and setar master Hossein 'Alizadeh (b. 1951) and the kemacheh master Kayhan Kalhor (b. 1963) have found significant audiences for their music both in Iran and overseas via the world music market of the West that emerged during 
the 1980s. ${ }^{2}$ Hossein 'Alizadeh's long career began before the revolution and he is strongly based in performing with the procedural model, where the gusheh of the radif serve as a starting point for a larger improvised performance framed by composition within a dastgah or avaz-dastgah. Yet over his career he has also composed and improvised using dastgah as abstract modality in many different frameworks, at times alternating between his full knowledge of radif, procedural performance, and abstract modality. Kayhan Kalhor's recording career began after the revolution while based overseas. His first album, Scattering Stars Like Dust, relied heavily on his own particular style of improvisation upon abstract modality. ${ }^{4} \mathrm{Kal}-$ hor's greater use of abstract modality has facilitated a larger amount of work on the world music market in fusion collaborations with non-Iranian performers, including Indian fusion with the Hindustani musician Shujaat Khan, a Turkish collaboration with Erdal Erzincan, and a Kurdish and German Jazz collaboration with Aynur, Salman Gambarov, and Cemîl Qoçgirî.. Being able to think of Iranian music as a set of modes with only general parameters of pitch facilitates greater collaboration with other music traditions, where Iranian musical identity can be put in conversation with other identities.

Despite concerns about losing the long-form, procedural model of performance to radif-playing and abstract modality, both 'Alizadeh and Kalhor began performing together primarily using the procedural model in the early 200os. As the core instrumentalists in the Masters of Persian Music, they performed live with the singer Mohammad Reza Shahjarian (b. 1940) and his son Homayun Shahjarian (b. 1975), who both sang and played percussion. While considered a niche format with limited audience appeal, the procedural model of performance remains compelling because it privileges the voice and the fusing of musical representation with linguistic representation, where music facilitates ancient poetry at the heart of Iran's modern cultural identity. Within this setting, increasing the use of tasnif can further create a musical frame for ancient Iranian poetry that acknowledges the realities of Iran in the modern world. Bringing together top performers in the tradition to perform using what is now considered an older, traditional form was a winning concept. The performances of The Masters of Persian Music were greeted with large audiences and much acclaim in Iran and overseas. ${ }^{6}$

While different approaches to performing the radif-dastgah tradition of Iranian music are subject to interpretation, the development of specific ideas for its systematic modality concretely rearranged aspects of the original seven dastgah. For instance, the extraction of the avaz-dastgah created more consistent modal frameworks and specifically removed large amounts of modal difference from Shur. With its newly created modal consistency, Shur became a central dastgah over and above seemingly more common dastgah in the past, such as Rast-Panjgah and Chahargah. While some musicians still attached some kind of special importance to Chahargah later in the twentieth century, any possible larger role of Rast-Panjgah in the initial seven dastgah would be rendered irrelevant 
once consistent shared pitch structure became a defining feature of the system. ${ }^{7}$ While it seemed as if certain gusheh were evolving toward becoming their own avaz-dastgah in the late twentieth century, these gusheh were reflecting an older manifestation of the tradition, where more modal variation could be part of the normal framework of performance. These gusheh behaved in relation to the tradition's past rather than an ever-evolving future, yet were reinterpreted to represent "modulation" in order to give them a rational place in the conception of dastgah as primarily rational modes.

In this sense, which modal frameworks musicians ultimately chose for composition determined which parts of the dastgah were separated into avaz-dastgah. The avaz-dastgah of Shur and Homayun took on musical lives of their own, with strong modal identities that were as applicable in composition as the modal frameworks musicians identified for the dastgah from which they were extracted. For instance, in the old tasnif recalled by Davami, there were twenty for Bayat-i Isfahan, but only nineteen for Homayun, the dastgah from which Bayat-i Isfahan was extracted. As a modal framework for composition, Bayat-i Isfahan had become equal to Homayun in importance. Being one of the original seven dastgah did not guarantee consistent dominance in performance once systematic modality became a key conceptual framework in the tradition. The avaz-dastgah became as popular as many of the dastgah for use in performance, and even more popular than the least modally consistent dastgah of Nava and Rast-Panjgah.

The avaz-dastgah could not be considered truly independent, however, without their own fully formed procedures to deliver the ancient poetry. Once listed as single specific melodic sections within the dastgah, the avaz-dastgah developed with their own unique short series of gusheh, with their distinct daramad apparently added later. Just as each dastgah's performance was designed to accommodate multiple couplets of ghazal, the avaz-dastgah encompassed similar if shorter poetic formats. The development of the avaz-dastgah demonstrated that, while the tendency to compose in specific smaller aspects of dastgah played a key role in what parts of dastgah would become avaz-dastgah, each smaller aspect of a dastgah also needed to be able to facilitate the sequencing of ancient poetry in the same format of the dastgah. Even with the increase of composition and the application of new poetry in the tasnif, the ancient poetry never stopped being a factor in the tradition even with significant change. Poetry itself acted as its own, third consideration, next to systematic modality and the radif that musicians could manipulate to define the music's structure in light of Iranian identity.

While having these three distinct categories of analysis to manipulate has allowed for the music to change in a variety of ways. changes in systematic modality, the radif, and poetry also can influence and inhibit one another in interesting ways. New gusheh in the radif could be added and classified based on systematic modal application. While new gusheh could facilitate poetry, they often did not. Instrumental radifs grew in size and proliferated as the twentieth century pro- 
gressed, adding more and more melodies of vague origin, yet tied concretely to the actual modern borders of Iran. While Forsat spoke of the melodies of the dastgah being historically Persian and ancient in some general sense, the idea that different regions of the actual modern nation of Iran were or should be represented in the radif fed into the development and documentation of different instrumental radifs in the twentieth century. With instrumental versions coming to contain more melodies than vocal versions, the distinction of systematic modality facilitated the inclusion of new gusheh melodies independent of poetry and an ability to imagine how music could represent the entirety of Iranian culture as a single musical whole. Within this concept of the tradition, the original place of poetry in the music's organization could be marginalized by the more abstract representation of identity that music could provide.

But systematic modality also facilitated more composition, including more instrumental pieces and the tasnif, which opened up avenues of modern literary expression in the tradition. Tasnifs were open to use language the citizenry could understand, and addressing the citizenry of Iran became a standard aspect of tasnif poetry. Thus composition could also marginalize the notion of radif. Distinguishing abstract modes from distinct melody, and a category of composition that specifically contrasted with the concept of improvisation, could also deem the radif irrelevant. A musician could simply take a scale and improvise upon it or use it to compose, without reference to the melodies of the radif. Musicians did not have to learn all the melodies of the radif, if they could just create new melodic material using modes.

By distinguishing between these three categories of the music's structure and performance, musicians created three ways to change the tradition. Each category of change could validate Iranian identity in different ways. But in distinguishing these structures in relation to modern Iranian identity, musicians had choices to make about how to approach the system. If musicians wanted a system of fully systematized modality, they would lose the ancient Iranian melodies and the ancient Iranian poetry. If musicians wanted to focus on radif, they could not apply systematic modality as they pleased, and they needed to abide by the procedures of the melodies themselves. If ancient poetry was central to performance, the number of melodic possibilities could decrease.

With so many different factors validating the Iranian nature of the music, it would not ultimately become a fully rationalized system of systematic modality. Some dastgah kept sections that lacked modal consistency. Not all modal possibilities became distinct models for composition and performance. While Karimi's later version of the vocal radif was larger than Davami's, it did not deviate from the basic organizing principles of the original tradition: the same genres of poetry still mattered. Yet the notion of radif increased the importance of melodic procedure, with or without reference to poetry. It came to embody its own grant design of melodic organization. 
In all these ways, the radif-dastgah tradition has been engaged in a modern negotiation of Iran's national identity and this negotiation has framed multiple approaches to performance in its relatively short history. Actions taken regarding the radif-dastgah system's structure and application in practice have had a unique role in shaping the nation of Iran. While many tasnif addressed the state of the Iranian nation very early on, the music itself also addressed the Iranian nation and spoke on its behalf. The radif-dastgah tradition had to specifically speak to the Iranian people, their history, and their culture on a variety of levels both implicit and explicit. The radif-dastgah tradition told Iranian audiences and the world about Iranian identity, both affirming this identity and educating audiences on the nature of the identity. It is not merely a practice of custom. It is a performance of the nation, which made and continues to make Iran a real place. In a modern world with so many mapping possibilities for nation-states, the radif-dastgah tradition validates one particular nation and provides evidence of its legitimacy in the modern world.

\section{THE TWELVE-MAQAM SYSTEM IN HISTORICAL PERSPECTIVE}

The world of the radif-dastgah tradition ultimately emphasizes the subjectivity of music in relation to Iranian identity, yet the twelve-maqam system represents a way of thinking about music grounded in notions that music is distinct from any one human context, while objectively relating to the laws of the natural world and humanity as a whole. While musicians of the radif-dastgah system pursued answers to questions about what the true Iranian music was or should be, the concept of music that made the twelve-maqam system relevant asked questions about the natural order of the universe, and the most perfect organization of music that could be aligned with this natural order.

The twelve-maqam system existed within certain geographies and temporal spaces, yet its definition was built on a concept of proper existence that was universal and timeless. But anyone familiar with the twelve-maqam system was capable of understanding when another method of music-making was different. The universality of the twelve-maqam system defined it as relevant to polyglot populations and writings about the twelve-maqam system acknowledge that there are many different kinds of people in the world. Yet there was no notion that there was a world of nations or races that produced distinct music traditions according to their distinct identities. Regional variation grounded in changing subjective preferences was not a desirable basis for music-making and thus the same musical and cosmological concepts often underpinned musical difference. Even when music was different from the twelve-maqam system, somehow it was the same.

Historically, the subjectivity taken for granted in the radif-dastgah tradition was a problematic weakness that needed to be managed vis-à-vis musical expres- 
sion. The problem of musical morality in the world of the twelve-maqam system was the extent to which music's inherent power could help or harm humanity in light of their imperfect, subjective perceptions. Divinity and evil existed in a state of cosmic objectivity for which the twelve-maqam system attempted to account. Yet the totality of cosmic existence was beyond the capacity of human subjective perception. In this framework, humanity judging the world using its own, imperfect subjectivity was an imperfect and dangerous proposition. With proper demonstrable ties to the cosmos, music could help a person overcome limited subjectivity to find contact with the divine. Yet the weakness of human subjectivity could also pervert a person's ability to engage properly with any source of power that influenced humanity via the ears.

While writings about the radif-dastgah tradition indicate the modern political reality taking shape in the nineteenth and early twentieth centuries, sources on the twelve-maqam system connect it to a separate political order. For as much as the radif-dastgah tradition had to relate to a unique conception of Iranian culture and history, the twelve-maqam system provided a model of musical structure that related to the cosmopolitanism of empire at its dynastic centers of power. The dynastic courts of its patronage related to the contingencies of how empires rose and fell in Western Asia between the thirteenth and nineteenth centuries. The extent to which any given dynasty maintained continuity - and the extent to which new empires took on the trappings and resources of the empires they defeateddetermined the geographical distribution of the twelve-maqam system over time. As musicians moved from one court to another, the twelve-maqam system moved with them. In the same way that music did not maintain a specific relationship with any one ethnolinguistic culture, it also did not maintain a fixed geographic location or operate according to regional or linguistic exclusion.

The dynastic realm as a model of governance was not static, and though new dynastic realms were typically built out of the institutions of older realms, they also embodied distinctions of rule over time. The Islamic Empires that grew out of Turkic and Mongol rule in West, Central, and South Asia introduced the most dramatic changes to the dynastic model of governance beginning in the sixteenth century. The Safavid Empire's particular approach to rule at this time had unique implications for music. The importance of the ruling dynast initially intensified in Safavid music culture within their centers of power, and the need to directly perform Safavid dynastic power changed the priorities of music-making. As the Safavids developed a highly performative approach to demonstrating their power, music gained standing as an explicit actor in the portrayal of Safavid power. Their fall in the eighteenth century effectively weakened the relevancy of the twelvemaqam system, as its dynastic context fell into a period of disarray that was unprecedented in this music system's period of dominance. These contingencies of Safavid rule resulted in a strong break in court music between the Safavids and the Qajars. 
The structural differences between concepts inherent in the twelve-maqam system and those underlying even the earliest versions of the seven dastgah reflect an initial distinction between music traditions that had long held strong connections to dynastic life and those that did not. The twelve-maqam system's context was unusually literate, as dynastic aristocracies maintained higher levels of literacy than their largely nonliterate subjects. Just being able to read and write about music was an exceptional phenomenon. For whatever regional musical features the twelve-maqam system embodied, its emphasis on a high degree of codified structure reflected its literate dynastic context. It likely was not the most common approach to music-making for most Persian-speakers historically, or Arabicspeakers, or Turkic-speakers. It was the music of the dynastic ruling class, and dynastic rulers existed above and beyond the realities of their subjects, within a plane of knowledge and power intentionally restricted and kept apart from dynastic subjects. In this sense, it's possible that procedural models of practice are much older than what written documentation suggests. They represent an indigenous approach to music-making that could be more broadly accessible than the twelvemaqam system and highly functional in strictly oral contexts.

Regardless, the goal of any dynastic realm was universal domination of territory and resources. On this basis, the twelve-maqam system's representation of a universally applicable music system matched the political realities of the porous, ever-changing borders of empire. It represented a specific musical reality of an equally specific cultural order, a cultural order that required universal applicability, even as music remained a much more localized activity in most of the world. Music for dynastic rule had to accommodate the political goal of conquering as much land and as many resources as possible. With divinely endowed power and military might validating rule over any number of places and subjects, the music of the political aristocracy had to relate to both structural realities of the cosmos and any given dynast's push for universal dominance.

\section{PERSIAN MUSIC IN HISTORICAL PERSPECTIVE}

Writings about the twelve-maqam system model a high degree of ideal structural consistency over time, as do the concomitant writings about sama ${ }^{\circ}$. There are several basic categories of information any text may address, and very little information is included outside of these categories. They could be built out from a certain core model of presentation, but even the addition of topics followed a certain logic and had set limitations. In this way, the topics covered and how they were discussed demonstrate a great degree of consistency within their variety over several centuries. The universalism at the center of how music was conceived was equally central to how music's content and meaning were analyzed.

From the very beginning, writings about the radif-dastgah tradition followed no particular model and demonstrated more variety of content and structure 
over a much shorter period of time. They used a variety of structures and presented a variety of goals and interests. All of this variety was further grounded in modern concerns. These concerns included reporting on the common practice of specific musicians, dictating modern scientific knowledge, reinterpreting musical norms, reorganizing and moralizing historiographic narrative, and developing pedagogical processes in relation to national history.

Reading these texts seeking to understand music culture provides a very different view of history than reading them to understand a more narrowly defined truth of musical practice. In pursuing the truth of what musicians "were really doing" with the twelve-maqam system, culture often takes on a marginalized role in understanding the music. Texts have to be parsed to find the information modern scholars want concerning how people made music in the past, even as this leaves most statements about music unaccounted for. Statements deemed unuseful for understanding musical practice in real time are the missing information that reveals what made broader categories of music's conception and practice possible. They relate to the essence of the music culture itself and demonstrate the connection between music and the broader context in which it operates.

These broader contextual questions define the possibilities of musical practice in larger temporal spaces, where music is unlikely to be practiced in a single way. In the same way Iranian music could be structured in various ways to address the modern Iranian context, the twelve-maqam system did not have to have one specific version or fully realized idealization that was universally correct for the duration of its dominance. Broader context provides a framework for understanding a music's cultural epistemology, and the parameters of musical possibility any particular epistemology can facilitate.

Many of the specific details of musical practice throughout history are simply unknowable. But the temporal-cultural order is often knowable and can provide a framework for understanding the limits of music's conception and practice. Rather than assuming that there is a single Persian music, and imposing a specific a priori cultural category on music historiography, music itself can provide a window into what culture was historically, and provide a more specific definition to the relationship between music and culture that is demonstrable on specific terms. Most significantly, it can account for change and demonstrate music's active role in cultural production at different points in time.

From this perspective, the study of music history as an analysis of the cultural construction of events presents a useful framework for music history in the Middle East. In this methodology of historiography, music stands as something much more than a perennial marker of ethnolinguistic identity, delimited further by a fixed political or religious order. People can use music to both maintain and change the cultural order in active responses to specific historical realities. In this context, neither music nor people are static entities. Though either or both could exist in a relative state of stability within any given space, both have a perennial 
ability to change. The focus of music history within this framework becomes the active ways music interacts with the stability and instability of human life. Music is both an active subject of cultural adaptation and stability, as well as a contributor to adaptation and stability. This analysis reveals a more detailed conception of music's relationship with identity over time, even as it acknowledges the place of agency and the broader phenomena of contingency in relation to specific factors that can foster cultural stability and cultural change.

In considering the ways humanity can use music to actively create its context, Persian-speaking people become active participants in the cultural order, rather than passive recipients of an unchanging, preestablished cultural reality. Their adoption and application of different conceptions of music and musical practices occurred at the intersection of established cultural order, historical events, and the need to adapt to new social, economic, and political realities over time. When faced with the need for change, peoples of the Middle East did not simply stay the same, nor did they adopt new cultures wholesale. An indigenous cultural order provided materials and strategies for confronting change, and thus indigenous cultural practices like music became a first source of adaptation. Cultural orders of the region underwent multiple historical transformations before the rise of modernity, and each time indigenous cultural practices were a site to negotiate between established norms and new circumstances of existence.

It was within this type of process that modern peoples of the Middle East adopted many new musical ideas and practices, while also turning to indigenous ideas and practices to begin constructing indigenous forms of musical modernity vis-à-vis the West. Any number of contingencies could intervene, yet people still needed indigenous music aesthetics and had enough agency to interpret them in such a way as to support modern norms of existence.

Though modernity's global economic system brought extreme amounts of global power to the Western world, it also brought the presumption of cultural difference. Modernity fostered notions of race and nation that necessitated musical difference as part of the modern global order. Even as many Western norms of culture were adopted in different parts of the world, the need to preserve indigenous musical identity also stood as a part of modernization. Nationalist narrative put the golden age of the Iranian nation somewhere in the ancient past, but so did Orientalists from Europe. In this sense, Europe did not always come to destroy indigenous culture in favor of modern institutions and affect, nor did indigenous people adopt European perspectives on their history with no reference to indigenous experience. For all of their European education, neither Mehdi Qoli Hedayat nor 'Ali Naqi Vaziri advocated for mere abandonment of indigenous practice in favor of European music, or absolute maintenance of Iranian music in its imagined premodern state. Neither did they think about Orientalist perspectives and ideas exactly as Orientalists had presented them. Instead, European ideas fed into indigenous frameworks of mod- 
ern understanding, even as indigenous music changed in ways unique to the modern Iranian experience.

The influence of European music on the radif-dastgah tradition has been the focus of some scholarly speculation, and scholars have often tied the question of how modern the tradition is to the question of how much Western musical influence it adopted. For the disciplines of both ethnomusicology and Iranian musicology, musical modernity is often diagnosed using the introduction to Western music aesthetics within modern colonial settings. Yet core structures of the radifdastgah tradition were not conceived of in Western musical terms per se, nor were changes to its structures an introduction of mere imitations of ideas from Western music. They were specific imaginings of what Iranian music was and what it should be in relation to changing understandings of Iran's national history in a world of distinct national histories. Musicians were not always attempting to imitate Western music: they were also seeking to establish their own unique music in keeping with modern parameters of identity. In this sense the radif-dastgah tradition is as modern as any music produced over the past two hundred years in the West. It depends on modern concepts of identity and history and is defined by the project of modernity even in its most traditional forms of practice.

The anthropologist Marshal Sahlins was critical of the idea that capitalism and Western imperialism presented an existential threat to the existence of indigenous cultures. For all the West's power, Sahlins asserted, indigenous people outside of the West were still people with cultures and agency to act within and adapt to modern situations in culturally unique ways. He positioned modernization as a historical event that multiplied forms of cultural existence. He pondered this idea in the context of considering how many of the practices of indigenous peoples that anthropologists had originally considered ancient were in fact quite modern. In defining traditions as "culturally specific modes of change," he positioned tradition as something that had an explicit role in adapting to any historical event, and a specific role in indigenizing modernity. ${ }^{8}$

The notion of tradition as a location for culturally specific modes of change in the modern world is especially relevant to Iran, where the government has conspicuously couched its modern national identity using multiple conceptions of tradition: ancient Persian kingship for much of the twentieth century, and Shi a Islamic jurisprudence from the end of the twentieth century until today. Within the national awakening and creation of modern Iran, newly realized Iranians looked to the cultural practices in their midst to address the challenges presented by modernity, and to answer questions about their place in the modern world. Music became a focus of culturally moded change that could foster various degrees and types of indigenization within the context of modernity. Doing this helped create Iranian identity as a national cultural phenomenon.

In this more detailed context of tradition's relationship with culture and agency, the radif-dastgah tradition developed as a way of making music that spoke specifi- 
cally to the modern era in both conception and intent. The radif-dastgah did not evolve out of the twelve-maqam system, nor is such a model of ongoing evolutionary development viable or useful. Conversely, the radif-dastgah tradition is not a secondary system to the twelve-maqam system, or a lesser-developed system growing out of Iran's cultural decline because Iranians lost track of the twelvemaqam system in their music history. The radif-dastgah tradition is a method of music-making that lives within the indigenous negotiation of modernity.

The twelve-maqam system's dependence on universality could stand as a model of how things used to be done and musical proof of Iranian cultural history, but it lacked the structural idiosyncrasies needed to define it as uniquely Iranian. Within this modern push for national Iranian identity, the radif-dastgah offered options for musical interpretation that the twelve maqam could not offer, and these options proved significant in developing an indigenous music tradition for modern Iran. Within its own context, the radif-dastgah tradition became a more appropriate method of music-making than anything someone like Safi al-Din or Maraghi could have conceived. No amount of premodern musical training, intellectual study, or even pure genius could create a music system as appropriate to the modern Iranian experience as the radif-dastgah tradition.

The differences between the twelve-maqam system in its various guises and the radif-dastgah tradition in all its variations ultimately come to reflect different contexts of human existence that occupy distinct cultural spaces, as people interact with music in relation to different realities that exist at different points in time. From this perspective, scholars can discuss broadly shared trends in the musical practices of the Middle East throughout history, and many specific differences between the musics of regional and ethnolinguistic groups in modern practice. But narrating evolutionary models of music history where one music tradition gradually morphs into another over time in a single line of ethnolinguistic cultural development obfuscates the cultural differences that different methods of music-making can relate to at different points in time. In understanding that music is indeed part of and subject to culture, its relationship with specific conditions of existence cannot be ignored in any given time and place, nor can one understand music's meaning at any point in history without understanding the terms of human agency and the contingencies of history. 